\title{
The effect of tyrphostins AG494 and AG1478 on the autocrine growth regulation of A549 and DU145 cells
}

\author{
Agnieszka Bojko, Kinga Reichert, Anna Adamczyk, Joanna Ligęza, \\ Janusz Ligęza, Andrzej Klein
}

Department of General Biochemistry, Faculty of Biochemistry, Biophysics and Biotechnology, Jagiellonian University, Krakow, Poland

\begin{abstract}
We employed two selective EGFR tyrosine kinase inhibitors: AG494 (reversible) and AG1478 (irreversible) for growth regulation of human lung (A549) and prostate (DU145) cancer cell lines, cultured in chemically defined DMEM/F12 medium. Both tested tyrphostins significantly inhibited autocrine growth of the investigated cell lines. The action of AG494 was dose dependent, and at highest concentrations led to complete inhibition of growth. AG1478 seemed to be more effective at lower concentrations, but was unable to completely inhibit growth of A549 cells. Inhibition of EGFR kinase activity by AG494 in contrast to AG1478 had no effect on the activity of ERK in both cell lines. Both EGFR's inhibitors induced apoptosis of the investigated lung and prostate cancer cell lines, but the proapoptotic effect of the investigated tyrphostins was greater in A549 than in DU145 cells. The tyrphostins arrested cell growth of DU145 and A549 cells in the G1 phase, similarly to other known inhibitors of EGFR. The influence of AG494 and AG1478 on the activity of two signaling proteins (AKT and ERK) was dependent upon the kind of investigated cells. In the case of DU145 cells, there was an evident decline in enzymatic activity of both kinases (stronger for AG1478), while in A549, only AG1478 effectively inhibited the phosphorylation of Akt. Tyrphostins AG494 and AG1478 are ATP-competitors and are supposed to have a similar mechanism of action, but our results suggest that this is not quite true. (Folia Histochemica et Cytobiologica 2012, Vol. 50, No. 2, 186-195)
\end{abstract}

Key words: epidermal growth factor (EGF), epidermal growth factor receptor (EGFR), tyrphostins, A549 cells, DU145 cells, autocrine growth regulation

\section{Introduction}

Lung and prostate cancer are the commonest causes of death among all malignant carcinomas in the world, because they are mainly diagnosed in advanced and refractory stages of the disease. An important early event in the development of the neoplastic phenotype is the induction of genes involved in autocrine growth regulation, such as growth factors and their receptors. An increased production of transforming growth factor $\alpha(\mathrm{TGF} \alpha)$ or epidermal growth factor

Correspondence address: A. Bojko, Department of General Biochemistry, Faculty of Biochemistry, Biophysics and Biotechnology, Jagiellonian University, Gronostajowa Str. 7, 30-387 Krakow, Poland; e-mail: agnieszka.bojko@uj.edu.pl
(EGF) and its receptor (EGFR) involved in autocrine regulation of cell growth has been found in several lung and prostate cancer cell lines, including A549 and DU145 $[1,2]$. Irregular downstream signalization is a crucial factor in cancer development and progression, because it controls proliferation, apoptosis, angiogenesis, tumor invasiveness and metastasis [3] and even drug resistance or response to radiotherapy $[4,5]$.

Therefore, the family of EGFs receptors emerges as an attractive target in anti-cancer therapy. One of the most promising ways of inhibiting the transduction signal via EGFR are low molecular tyrosine phosphorylation inhibitors (tyrphostins), recently developed as synthetic tyrosine kinase inhibitors by Levitzki [6] and Levitt [7]. These compounds can also be a useful tool in investigations of autocrine growth 
regulation of cancer cell lines. In the present work, we tested two tyrphostins: AG494 and AG1478 in the autocrine growth regulation of human non small cell lung cancer cells (NSCLC; A549; derived from cancerous lung tissue) and human prostate cancer cells (DU145; derived from brain metastasis). Both the investigated compounds are specific ATP-competitive inhibitors of tyrosine kinase, located in the intracellular domain of the EGFR. However, tyrphostin AG1478, unlike AG494, acts in a non-reversible manner $[6,8,9]$. Also, AG1478 structurally is very similar to clinically used erlotinib (Tarceva ${ }^{\mathrm{TM}}$ ) and gefitinib (Iressa ${ }^{\mathrm{TM}}$ ), which implies it has a potent anti-cancer application. We tried to evaluate the tyrphostins' influence on proliferation, viability and signaling pathway via EGFR, ERK and Akt protein kinases.

\section{Materials and methods}

Chemicals and reagents. Dulbecco's modified minimal essential medium (DMEM), minimal essential medium (MEM), fetal bovine serum (FBS), 10,000 IU/ml penicillin and $10 \mathrm{mg} / \mathrm{ml}$ streptomycin were purchased from PAA Laboratories $\mathrm{GmbH}$, Austria. Bovine serum albumin (BSA), transferrin, trypsin, taxol, Hoechst No 33342, Crystal Violet, propidium iodide (PI) and tyrphostins: AG494 and AG1478 (kinase inhibition $\mathrm{IC}_{50}: 1.2 \mu \mathrm{M}$ and $3 \mathrm{nM}$, respectively, values were taken from the manufacturer's leaflets), dimethyl sulfoxide (DMSO), ethylenediaminetetraacetic acid (EDTA), (3-(4,5-dimethylthiazol-2-yl)-2,5-diphenyltetrazolium bromide (MTT) were obtained from Sigma (St. Louis, MO, USA). Other reagents were provided by POCh (Gliwice, Poland). ERK CASE Kit and Akt CASE Kit were purchased from SABiosciences (Valencia, CA, USA). Stock solutions of the tyrphostins were prepared by dissolving the compounds in dimethylsulfoxide (DMSO) to a final concentration of $50 \mathrm{mM}$ and storing the resultant solutions at $-20^{\circ} \mathrm{C}$. DMEM/F12 (1:1) medium was used to dilute stock solutions to working concentrations (AG494: 1-20 $\mu \mathrm{M}$ and AG1478: 0.1-8 $\mu \mathrm{M})$.

Cell culture. DU145 (HTB-81) and A549 (CCL-185) cells were obtained from the American Type Culture Collection (ATCC) and cultured in MEM or DMEM, supplemented with $100 \mathrm{IU} / \mathrm{ml}$ penicillin and $100 \mu \mathrm{g} / \mathrm{ml}$ streptomycin in the presence of $10 \%$ fetal bovine serum (FBS) and non essential amino acids (NEAA). The cells were passaged two or three times per week.

Cell proliferation assays. Target cells were seeded on 96-well plates at concentrations of $4 \times 10^{3}$ cells/well in MEM (DU145 cells) or DMEM (A549 cells), supplemented with $100 \mathrm{IU} / \mathrm{ml}$ penicillin and $100 \mu \mathrm{g} / \mathrm{ml}$ streptomycin in the presence of $10 \%$ FBS. Following $24 \mathrm{~h}$ of incubation, the culture medium was replaced with serum-free DMEM/F12 (1:1) supplemented with transferrin $(5 \mathrm{mg} / \mathrm{ml})$, sodium selenite $(2 \mathrm{ng} / \mathrm{ml})$ and albumin $(0.5 \mathrm{mg} / \mathrm{ml})$ [DMEM/F12+]. After an additional $24 \mathrm{~h}$ of incubation (Day 0 ), the medium was replaced by serum-free DMEM/F12 + medium containing tyrosine kinase inhibitors: AG494, AG1478 respectively in concentration ranges $1-20 \mu \mathrm{M}$ and $0.1-8 \mu \mathrm{M}$. The incubation was continued for the next $24 \mathrm{~h}$ at $37^{\circ} \mathrm{C}$ in a humidified atmosphere. The modified crystal violet staining method (CV) [10] and MTT assay [11] were used to determine the influence of the tyrphostins on the proliferation of target cells. The absorbance was measured using a Tecan (Spectra Fluor Plus) multiscan plate recorder. Ten replicate wells were used for each experiment. The effect of tyrosine kinase inhibitors was expressed as a relative (to the controls) decrease in cell growth determined after $48 \mathrm{~h}$ of incubation with the investigated compounds. The calculated parameter was:

$$
G_{i}=\frac{\overline{A_{i}}-\overline{A_{0}}}{\overline{A_{k}}-\overline{A_{0}}} \times 100
$$

where: $G_{i}$ - growth inhibition, $A$ - average values of absorbance: control at the start of experiments $\left(A_{0}\right)$, and after the time of incubation without $\left(A_{k}\right)$ and with $\left(A_{i}\right)$ the investigated compounds.

Assessment of cell viability. The double staining method (Hoechst 33342/PI) [12] was used in the investigation of the effect of tyrphostins AG494 and AG1478 on the viability of A549 and DU145 cells. The cells were seeded on 48-well plates at a density of $8 \times 10^{3} /$ well in $0.45 \mathrm{ml} \mathrm{DMEM}$ or MEM with $10 \%$ FBS. Following $24 \mathrm{~h}$ of incubation, the culture medium was replaced with serum-free DMEM/ $/ \mathrm{F} 12+$ medium. After an additional $24 \mathrm{~h}$ of incubation, the cells were exposed to investigate tyrphostins in concentrations previously outlined as $\mathrm{IC}_{10}, \mathrm{IC}_{50}, \mathrm{IC}_{90}$ and $20 \mathrm{nM}$ of taxol (positive control). The experiment was carried out for $24 \mathrm{~h}$ and then Hoechst 33342 and propidium iodide were added to the final concentration of $5 \mu \mathrm{g} / \mathrm{ml}$ and $1 \mu \mathrm{g} / \mathrm{ml}$, respectively. After $25 \mathrm{~min}$, the cells were directly examined on plates with a fluorescent Olympus IMT 2 microscope. One excitation filter (for UV light) was used, which allowed for excitation of both dyes. Image $\mathrm{J}$ software was used for image processing (merging RGB channels, enhancing contrast and sharpening) and the quantitative analysis of the processed pictures (cell counting). It allowed for estimating the fraction of dead cells (PI/DNA signal), viable cells (Hoechst 33342/DNA signal), and apoptotic cells (Hoechst 33342/DNA signal with morphological changes characteristic of late-phase apoptosis). Each experiment was repeated at least six times. Images with the number of cells exceeding approximately 100 were selected for the analysis.

Cell cycle analysis. To estimate the proportion of cells in various phases of cell cycle, cellular DNA contents were 
measured by flow cytometry (FACS). DU145 cells $\left(2.5 \times 10^{5} /\right.$ dish $)$ were plated on a Petri dish $(\varnothing 6 \mathrm{~cm})$ in MEM supplemented with $10 \%$ FBS and sodium pyruvate (MEM-NEAA). A549 cells in turn $\left(2 \times 10^{5} /\right.$ dish $)$ were plated on a Petri dish in DMEM supplemented with $10 \%$ FBS. Both cell lines were allowed to attach overnight. Subsequently, the cells were placed in DMEM/F12+ and incubated for another $24 \mathrm{~h}$. After this time, tyrphostins AG494 and AG1478 in concentrations previously outlined as $\mathrm{IC}_{50}$ and $\mathrm{IC}_{90}$ were added to the investigated cell lines. $48 \mathrm{~h}$ after the addition of the tyrphostins, the cells were harvested by trypsinization and centrifuged. The pellets were suspended in $1.0 \mathrm{ml}$ of cold PBS with $2 \%$ FBS and washed twice. The centrifuged pellets were suspended in $70 \%$ ethanol, fixed at $4^{\circ} \mathrm{C}$ for $2 \mathrm{~h}$ and centrifuged ( $7 \mathrm{~min}$ at $280 \times \mathrm{g} ; 1200 \mathrm{RPM}$ ). The pellets were then re-suspended in $5 \mathrm{ml}$ of PBS with $2 \%$ FBS and centrifuged again. The cells were stained with $1 \mathrm{ml}$ of propidium iodide (PI) solution (1 mg of RNAse A, $0.1 \mathrm{mg}$ PI, $5 \mu \mathrm{l}$ Triton X-100). Each sample was incubated at $37^{\circ} \mathrm{C}$ for $30 \mathrm{~min}$. DNA content was determined using a FACScan Beckton-Dickinson flow cytometer.

Evaluation of activity of ERK and Akt. To determine the influence of the investigated tyrphostins on the inhibition of kinase activity of signal molecules (ERK and Akt), we used the cell based CASE (Cellular Activation of Signaling ELISA) test. Two kinds of primary antibodies were employed: one antibody recognized only the activated (phosphorylated) form of the specific target protein, while the other recognized the specific target protein regardless of its activation state. The target cells were seeded on 96-well plates at a density of $5 \times 10^{3}$ cells/well in MEM (DU145 cells) or DMEM (A549 cells), supplemented with $100 \mathrm{IU} / \mathrm{ml}$ penicillin and $100 \mu \mathrm{g} / \mathrm{ml}$ streptomycin in the presence of $10 \%$ FBS. Following $24 \mathrm{~h}$ of incubation, the culture medium was replaced with serum-free DMEM/F12+. After an additional $24 \mathrm{~h}$ of incubation, the medium was replaced with serum-free DMEM/F12 + medium containing tyrosine kinase inhibitors: AG494, AG1478 in a concentration previously outlined as $\mathrm{IC}_{90}$ in four repetitions; while in the control wells, we replaced the culture medium with fresh DMEM/F12+. After three, six, 12 and 24 h, the cells were fixed with a solution of $4 \%$ formaldehyde in PBS. Then we continued the experiment according to the protocol [13] which was shipped by the kit manufacturer. We introduced a minor modification to the protocol, which involved time extensions of the incubation with blocking buffer (until $5 \mathrm{~h}$ ), primary antibody (until $12 \mathrm{~h}$ ) and secondary antibody (until $2 \mathrm{~h}$ ).

Statistical analysis. Statistical analysis was performed with the use of the GraphPad Prism 5.0 program. The effects of different tyrphostin concentrations on DU145 and A549 cells proliferation were analyzed using one way ANOVA, followed by Dunnett's test. The Mann-Whitney U test was used to determine differences in the percentage of alive, apoptotic and necrotic cells in the control sample versus tyrphostins or taxol (paclitaxel) treated samples. In the CASE method, statistical analysis was performed with the use of Statistica 9 program. The effects of EGFR inhibitors on phosphorylation of signal molecules Akt and ERK were analyzed using Fisher's test. Differences were considered significant at $\mathrm{p}<0.05$.

\section{Results}

\section{Effect of tyrphostins AG494 and AG1478 on DU145 and $A 549$ cell proliferation}

Human prostate cells DU145 and human lung cancer cells A549 were exposed for $48 \mathrm{~h}$ to tyrosine kinase inhibitors, added at the concentration range of 1-20 $\mu \mathrm{M}$ (AG494) and 0.1-8 $\mu \mathrm{M}$ (AG1478). Three repetitions were performed for each method. The effect of the investigated tyrphostins determined by $\mathrm{CV}$ and MTT assay is shown in Figure 1. The exposure of DU145 and A549 cells to tyrphostin AG494 and AG1478 resulted in a significant dose-dependent suppression of proliferation compared to the control cultures. Autocrine growth of the investigated cells, determined by the CV and MTT method, was practically completely inhibited at an AG494 concentration $\geq 15 \mu \mathrm{M}$ in A549 cells and $\geq 20 \mu \mathrm{M}$ in DU145 cells. Similarly, the growth of prostate cancer cells was completely inhibited at a concentration of AG1478 $\geq 8 \mu \mathrm{M}$. In turn, the growth inhibition curve of A549 cells showed a plateau at an AG1478 concentration $\geq 2 \mu \mathrm{M}$. The number of cells decreased to about $40 \%$ of control.

A $10 \%, 50 \%$ and $90 \%$ inhibition of the growth of A549 and DU145 cells was determined by fitting a sigmoidal model of the dose-dependent effect of the investigated tyrphostin (Table 1 ). $\mathrm{IC}_{10}, \mathrm{IC}_{50}$ and $\mathrm{IC}_{90}$ coefficients calculated from the growth inhibition curves (Figure 1) after $48 \mathrm{~h}$ of incubation were placed in Table 1. Due to the plateau on the growth inhibition curve of A549 cells treated with AG1478, it was impossible to calculate the $\mathrm{IC}_{90}$ value. Thus, in further experiments, we assumed a $90 \%$ inhibition of growth to be represented by the highest used concentration of EGFR inhibitor i.e $8 \mu \mathrm{M}$.

The results showed a higher cytostatic activity of tyrphostin AG494 in the case of A549 cells and a similar cytostatic activity of AG1478 in both of the investigated cell lines. The anti-proliferative activity (described by $\mathrm{IC}_{50}$ ) was higher than that parameter outlined in the producer's leaflet. In the case of AG494, $\mathrm{IC}_{50}$ was about five (A549 cells) or eight (DU145 cells) times higher, while in the case of AG1478, it was 300 times higher, regardless of the cell line. 

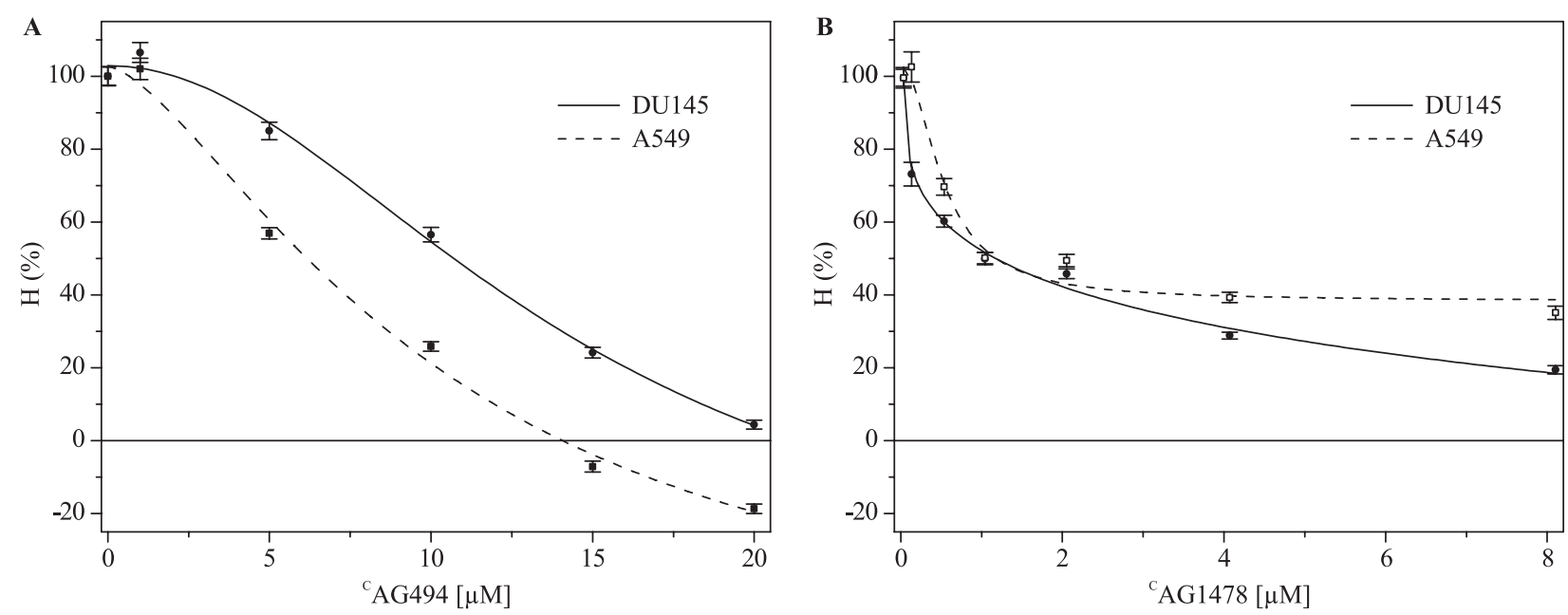

Figure 1. The dose-dependent effect of tyrphostins: AG494 (A) and AG1478 (B) on the growth of A549 and DU145 cells after $48 \mathrm{~h}$ of incubation in serum-free DMEM/F12+ medium. Each point is the average of the values determined by MTT and $\mathrm{CV}$ assay. $\mathbf{G}_{\mathbf{i}}$ - growth inhibition; $\mathbf{C}$ - concentration of used compound

Table 1. Values of $\mathrm{IC}_{10}, \mathrm{IC}_{50}$ and $\mathrm{IC}_{90}$ obtained from inhibitor curves of AG494 and AG1478

\begin{tabular}{|l|c|c|c|c|c|c|}
\hline \multirow{2}{*}{ Cell line } & \multicolumn{3}{|c|}{ Tyrphostin AG494 $[\mu \mathrm{M}]$} & \multicolumn{3}{c|}{ Tyrphostin AG1478 $[\boldsymbol{\mu M}]$} \\
\cline { 2 - 7 } & $\mathbf{I C}_{\mathbf{1 0}}$ & $\mathbf{I C}_{\mathbf{5 0}}$ & $\mathbf{I C}_{\mathbf{9 0}}$ & $\mathbf{I C}_{\mathbf{1 0}}$ & $\mathbf{I C}_{\mathbf{5 0}}$ & $\mathbf{I C}_{\mathbf{9 0}}$ \\
\hline A549 & $2.04 \pm 1.31$ & $6.20 \pm 1.26$ & $11.80 \pm 3.76$ & $0.23 \pm 0.18$ & $1.16 \pm 0.69$ & - \\
\hline DU145 & $4.49 \pm 2.73$ & $10.7 \pm 2.5$ & $18.4 \pm 6.43$ & $0.01 \pm 0.59$ & $1.17 \pm 0.61$ & $12.7 \pm 2.72$ \\
\hline
\end{tabular}

\section{Effect of EGFR inhibitors on A549 and DU145 cell viability}

The investigated tyrosine kinase inhibitors were also examined for their cytotoxic potential and the ability to induce tumor cell apoptosis or necrosis. As a positive control, the anti-neoplastic and anti-mitotic drug paclitaxel was used. Paclitaxel has been examined as a cytotoxic agent on various human cancer cell lines $[14,15]$. This taxane derivative binds to the tubulin and stabilizes microtubules, arresting the cell cycle at the $\mathrm{G} 2 / \mathrm{M}$ phase. The microtubule damage induces apoptosis [16]. The influence of tyrphostins AG494 and AG1478 on target cell viability was assessed after double-staining with Hoechst 33342 and propidium iodide. Viable cells were stained on dark blue with oval nuclei (gray in the black and white picture), apoptotic - light-blue (light gray in the picture) and necrotic cells - red (white in the picture). Apoptotic cells were clearly distinguishable by their characteristic morphology (cytoplasmic blebbing, cell shrinkage, nuclear condensation and fragmentation, the so-called apoptotic bodies) (Figure 2). The results of quantitative determination of the number of viable, apoptotic and necrotic cells are presented in Figure 3.

Both the investigated receptor kinase inhibitors affected the viability of DU145 cells in a similar man-

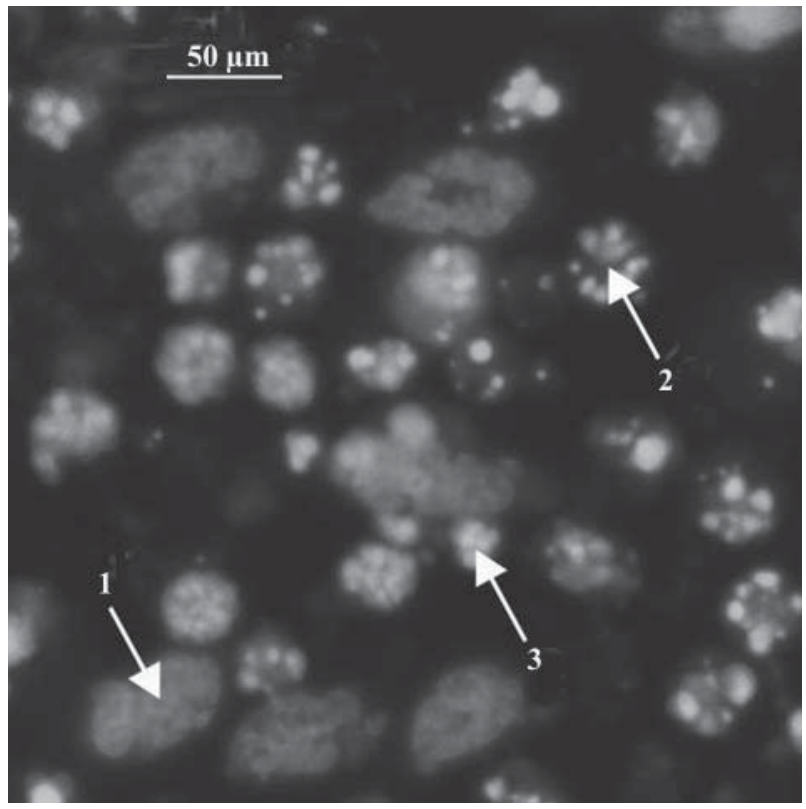

Figure 2. A typical picture of the cultures of DU145 cells after $24 \mathrm{~h}$ of incubation with $20 \mathrm{nM}$ taxol. 1 - viable cells; $\mathbf{2}-$ apoptotic cells; $\mathbf{3}-$ necrotic cells. Magnification $\times 200$

ner after $24 \mathrm{~h}$ of incubation in the serum-free medium, while A549 cells seemed to be more sensitive to AG494. In the case of the control culture of DU145 

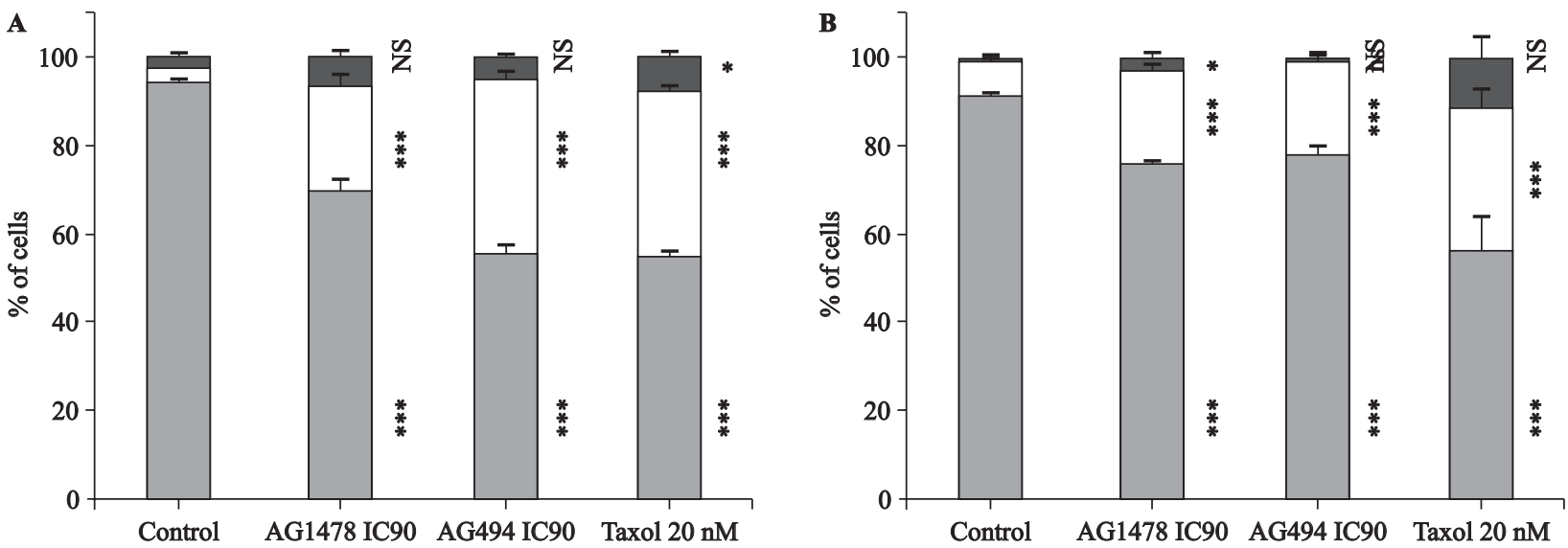

Figure 3. The cytotoxic effect of tyrphostins: AG494, AG1478 and taxol (as the positive control) in A549 (A) and DU145 cells (B), after $24 \mathrm{~h}$ of incubation in DMEM/F12+ medium. The average percentage of: viable cells (gray), apoptotic cells (white) and necrotic cells (black). Statistical significance: ${ }^{* *} \mathrm{p}<0.001 ;{ }^{*} 0.01<\mathrm{p}<0.05$; NS — not significant

and A549 cells, the number of apoptotic cells did not exceed $7.68 \pm 0.64 \%$ and $0.88 \pm 0.23 \%$ of the entire cell population respectively, while the number of necrotic cells was about $2.82 \pm 0.72 \%$.

The viability of DU145 cells cultured with AG494 and AG1478 was in the range $75.7-77.76 \%$ of the entire cell population, regardless of the kind of tyrphostin used. The percentages of apoptotic cells after incubation with AG494 and AG1478 increased to $21.32 \pm 2.07$ and $21.5 \pm 1.11 \%$, respectively. The number of necrotic cells differed, from $0.91 \pm 0.34 \%$ in the case of AG494, to $2.8 \pm 0.63 \%$ in the case of AG1478. The comparison of these results with the effect of $20 \mathrm{nM}$ taxol $(32.4 \pm 4.51 \%$ of apoptotic and $11.78 \pm 4.85 \%$ of necrotic cells) indicated that both investigated tyrphostins, used in the concentrations $18.4 \mu \mathrm{M}$ (AG494) and 12.7 $\mu \mathrm{M}$ (AG1478), were weakly cytotoxic for DU145 cells. The number of apoptotic and necrotic cells after DU145 incubation with both tyrphostins was similar. In contrast, in lung cancer cells treated with AG494 and AG1478, significantly lower viability than in the case of prostate cancer cells (respectively $55.35 \pm 1.85$ and $70.03 \pm 2.33 \%$ ) was observed. Furthermore, the number of apoptotic and necrotic cells differed from $23.81 \pm 2.08 \%$ and $6.16 \pm$ \pm 1.23 in the case of AG1478, to $39.68 \pm 1.54 \%$ and $4.97 \pm 4.94 \%$ in the case of AG494. The proapoptotic effect caused by AG494 in A549 cells was similar to $20 \mathrm{nM}$ taxol $(37.74 \pm 1.21 \%$ of apoptotic and $7.66 \pm$ $\pm 1.44 \%$ of necrotic cells).

\section{Influence of AG494 and AG1478 on cell cycle of DU145 and A549 cells}

DNA content of DU145 and A549 cells was determined by the use of a flow cytometer FACScan Beckton-Dickinson after $48 \mathrm{~h}$ of incubation with the in- vestigated compounds. The results are summarized in Table 2. Opposite differences compared to the control cell culture were observed after DU145 and A549 treatment with the investigated tyrphostins. Non-reversible AG1478 acted more strongly on the prostate cancer cell line than reversible AG494. This was unlike with lung cancer cells, where the situation was exactly the opposite. The increase in the number of cells in the G1 phase in DU145 was about $4 \%$ and $18 \%$ respectively after AG494 and AG1478 treatment, while the fraction of cells synthesizing DNA decreased by about $60 \%$ (only in the case of AG1478). In A549, unlike DU145, the increase in the number of cells in the G1 phase was much lower - $4 \%$ in the case of AG494 and only $2 \%$ in the case of AG1478, while the number of cells in the $\mathrm{S}$ phase decreased by about $20 \%$. The proportion of cells in phases G1 to G2 changed from 4.3 (control in DU145) to 5.5 in the case of AG494, and 8.0 in the case of AG1478 and, respectively, in A549 from 14.7 to 17.8 and 20.8 (Table 2).

\section{Evaluation of ERK and Akt activity in target cells treated with AG494 and AG1478}

Cell-based ELISA technique showed that AG494 had no influence on the level of phosphorylated ERK in both investigated cell lines. By contrast, AG1478 caused a significant decrease of ERK phosphorylation in A549 and DU145 cells and the effect was timedependent (Figures 4C, D). In prostate cancer cells treated with AG1478, phosphorylation of ERK decreased after $24 \mathrm{~h}$ of incubation to a value of 0.59 (the control value was equal to 1 ), but in lung cancer cells the effect was reversible (after $24 \mathrm{~h}$ the activity of ERK returned to the control value). After $3 \mathrm{~h}$ of incubation, both tyrphostins stimulated phosphorylation of Akt in DU145 cells, and only after $24 \mathrm{~h}$ was 
Table 2. The effect of AG494 and AG1478 on the proportion of DU145 and A549 cells in various phases of cell cycle. Cellular DNA contents were measured by flow cytometry (FACS) after $48 \mathrm{~h}$ of incubation with the tyrphostins

\begin{tabular}{|l|c|c|c|c|c|c|c|c|c|c|}
\hline \multirow{2}{*}{$\begin{array}{c}\text { Phase of } \\
\text { cell cycle }\end{array}$} & \multicolumn{4}{|c|}{ \% of cellular DNA in DU145 cells } & \multicolumn{5}{c|}{ \% of cellular DNA in A549 cells } \\
\cline { 2 - 13 } & Control & AG494 IC50 & AG494 IC90 & AG1478 IC50 & AG1478 IC90 & Control & AG494 IC50 & AG494 IC90 & AG1478 IC50 & AG1478 IC90 \\
\hline G1 & 62.6 & 66.1 & 66.1 & 73.0 & 80.5 & 76.6 & 77.0 & 81.0 & 78.1 & 78.2 \\
\hline G2 & 14.5 & 13.8 & 12.6 & 13.3 & 10.0 & 5.2 & 5.1 & 4.6 & 4.6 & 3.8 \\
\hline S & 22.9 & 20.0 & 21.3 & 14.7 & 9.5 & 18.2 & 18.0 & 14.5 & 17.4 & 17.9 \\
\hline G1:G2 & 4.3 & 4.8 & 5.3 & 5.5 & 8.0 & 14.7 & 15.1 & 17.8 & 17.0 & 20.8 \\
\hline
\end{tabular}

an evident decline of activation of that protein observed (with a stronger effect for AG1478) (Figure 4B). The investigated tyrphostins exerted an opposite effect on A549 cells - AG494 at first excited the phosphorylation of Akt and then highly inhibited this process, but AG1478 initially strongly inhibited the phosphorylation of Akt and even after $24 \mathrm{~h}$, the activity of that protein did not exceed the control value (Figure 4A)

\section{Discussion}

It is widely accepted that autocrine growth regulation is at least partly responsible for the development of cancer. Dysregulation of EGFR activation is implied in numerous human cancers (e.g. brain, lungs, breast and prostate) $[17,18]$. Oncogenic activation of EGFR may have diverse origins, and one of the mechanisms is overexpression of growth factors and its receptors. EGF/EGFR or TGF $\alpha / E G F R$ autocrine loops are well documented in both lung and prostate cancer cells $[1,2,19]$. The A549 cells exhibit overexpression of wtEGFR (80\%) [3] while DU145 mainly mutated EGFRvIII [3, 20, 21]. According to the above features, we used these lung and prostate cancer cell lines as a model of EGFR-induced cancer.

Various approaches have been used to inhibit or down-regulate neoplastic growth of prostate and lung cancer using taxol, genistein, erbstatin, soluble receptors, pseudoligands, monoclonal antibodies for tyrosine kinase receptors and synthetic receptor tyrosine kinase inhibitors (tyrphostins). We compared the activity of two tyrphostins: AG494 (reversible) and AG1478 (non-reversible) on the growth of A549 and DU145 cell lines.

The results described in this paper indicate that the blockade of EGFR signaling pathways by tyrphostins AG494 and AG1478 inhibits proliferation and viability of the investigated cells in vitro. $\mathrm{IC}_{50}$ determined by two different methods was similar for tyrphostin AG1478 (1.16-1.17 $\mu \mathrm{M})$ independent of the kind of investigated cells, and differed slightly for
AG494 (6.16 $\mu \mathrm{M}$ in A549 and $10.7 \mu \mathrm{M}$ in DU145 cells). The obtained data suggests that the EGF/TGFa autocrine loop induces a specific signaling route, which determines the cell's fate. Our results indicate that AG494 at a concentration $>15 \mu \mathrm{M}$ is able to completely inhibit A549 and DU145 autocrine cell growth, in contrast to tyrphostin AG1478 which when used at a concentration $\geq 2 \mu \mathrm{M}$ decreased cell growth of A549 to $40 \%$ of control. This could be caused by several factors. First of all, AG1478 has a higher affinity to mutated forms of EGF receptor, overexpressed in DU145 cells [3, 22, 23]. Therefore, proliferation of DU145 cells (which exhibit overexpression of EGFRvIII) [20, 21] after AG1478 treatment was almost completely inhibited. The second possibility is a heterogeneous population of lung cancer cells, with partial resistance to the used compound. Resistance to AG1478 might be caused by a multi-drug resistance mechanism (which has been described in many patients with lung cancer [24]) in A549 cells.

The anti-proliferative activity (described by $\mathrm{IC}_{50}$ ) was higher than that parameter outlined in the producer's leaflet. In the case of $\mathrm{AG} 494, \mathrm{IC}_{50}$ was about five (A549 cells) or eight (DU145 cells) times higher, while in the case of AG1478 it was 300 times higher, regardless of the cell line. Probably $\mathrm{IC}_{50}$ coefficient in producer's leaflet was obtained for an isolated form of EGFR kinase. The investigated tyrphostins act like ATP competitors. Inside living cell concentration of ATP is relatively high, so ATP itself could alter interaction between tyrphostin and EGFR kinase. As a result higher concentrations of EGFR inhibitors are required in cells. Then, tyrphostins are able to effectively bind to ATP-binding pocket in the kinase domain of the receptor. This process in turn prevent from ATP binding and receptor activation.

The main difference in the effect of AG494 and AG1478 is the different kinetics of A549 cell growth inhibition. This data suggests various mechanisms of growth inhibition. That hypothesis was only partly supported by the results of the effect of the investigated tyrphostins on the phosphorylation of some sig- 

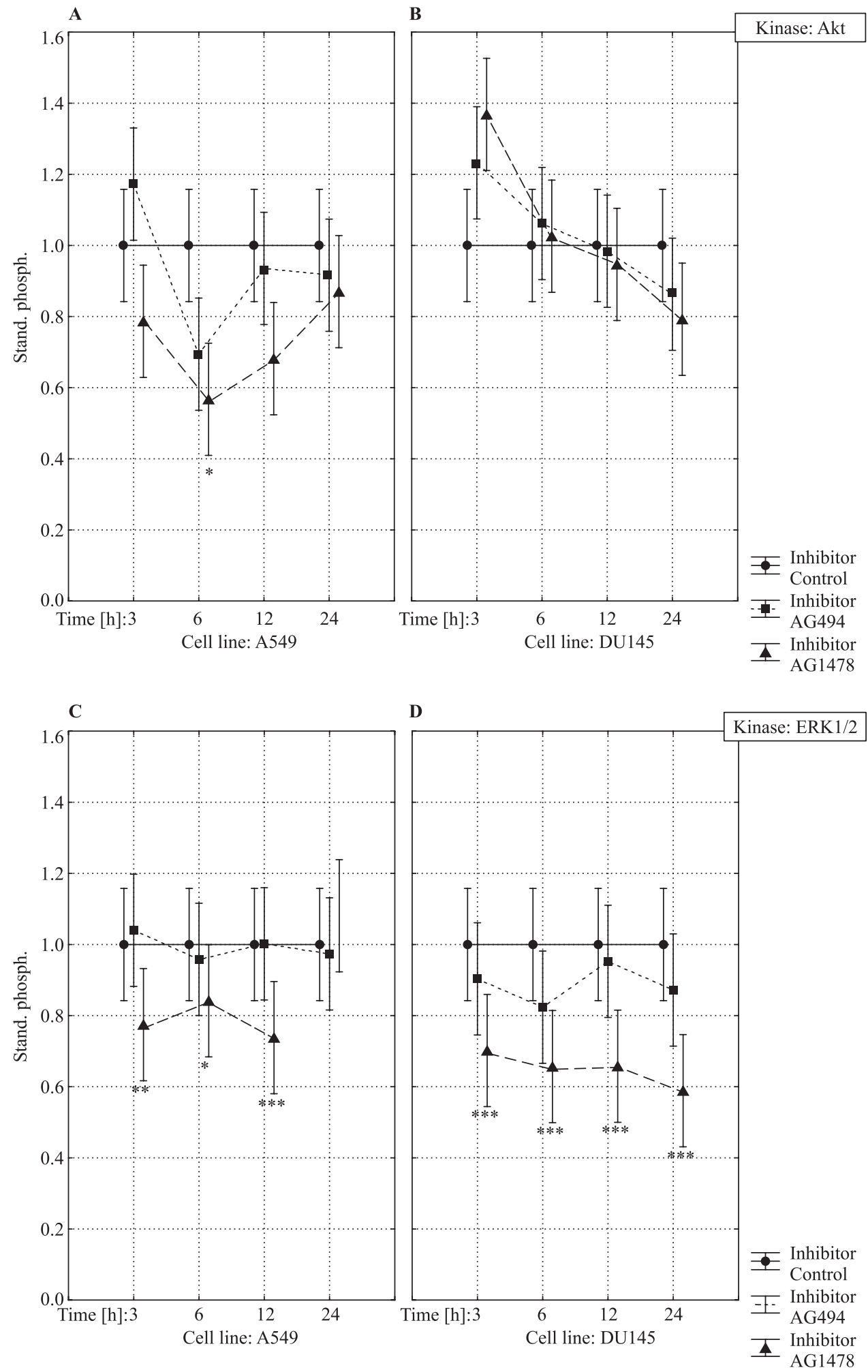

Figure 4. Time-dependent influence of tyrphostins AG494 and AG1478 on phosphorylation of signal molecules in target cell lines. The activity of Akt and ERK after treatment with investigated tyrphostins is shown in relation to their activity in the controls. Only points with statistical significance were marked as follows: ${ }^{* *} \mathrm{p}<0.001 ;{ }^{* *} 0.001<\mathrm{p}<0.01 ;{ }^{*} 0.01<\mathrm{p}<0.05$

nal proteins. The results obtained from the CASE test could prove that AG494 does not affect the activity of ERK (no effect on protein phosphorylation in both target cells was observed), which is supported by the available literature data [9]. Despite the fact that AG1478 does not show complete inhibition of growth, it significantly inhibits the activity of ERK in both cell lines (more strongly in DU145 cells). Most likely this 
is due to the fact that AG1478 inhibits the activity of Src, which in turn may be involved in further activation of the MAP cascade [25, 26, 28]. This kinase is involved in the signaling responsible for mitosis, adhesion, invasiveness, motility and progression of cancer cells [19, 25-27]. Src can directly interact as a substrate or activator with active EGFR. After activation, it may in turn phosphorylate EGFR, which leads to an increase in the activity of receptor's tyrosine kinase (positive feedback coupling) [26, 28]. A decrease in ERK activity can inhibit cell proliferation by a lack of adequate stimulation of cyclin-dependent kinases [1, 30, 31] or transcription factors (c-fos, c-myc, c-jun) [32]. The impact of target inhibitors on the phosphorylation of Akt is dependent on cell line. In the case of lung cancer cells, we observed (after $6 \mathrm{~h}$ of incubation) a higher decrease in activity than in prostate cancer cells for each of the investigated tyrphostins. Inhibition of the phosphorylation of the Akt may on the one hand cause apoptosis (e.g. lack of inactivation of the pro-apoptotic protein $\mathrm{Bad}$ ), and on the other hand, inhibition of proliferation (such as induction of the $\mathrm{p}-53$ protein responsible for cell cycle arrest) [30,33]. In prostate cancer cells, the activity of Akt and ERK even after $24 \mathrm{~h}$ did not exceed the control value, while in lung cancer it did. This may be caused by the presence in A549 cells of additional autocrine loops $[1,2,19]$. For example, the TGF $\alpha /$ /EGFR autocrine loop can induce the production of VEGF within the lung cancer cell, which in turn leads to activation of signalization via VEGFR [34, 35]. Then even the blockade of EGFR activity by investigated tyrphostins does not alter the activity of signal molecules like Akt and ERK. This may be the mechanism by which cells are able to find alternative signaling pathways. The described phenomenon could explain the curve plateau of growth inhibition caused by AG1478 in A549 cells. Induction of VEGFR by TGF $\alpha /$ EGFR autocrine loop leads to phosphorylation of ERK. Thus, blockade of EGFR activity by AG1478 in lung cancer cells is an insufficient factor to inhibit proliferation of these cells.

The differential staining method showed that the investigated tyrphostins, used at concentrations $\leq 18$ $\mu \mathrm{M}$ (AG494) and $\leq 13 \mu \mathrm{M}$ (AG1478), had little necrotic effect on the DU145 cell line, and indeed in the case of the A549 cell, this process was not observed. However, both investigated tyrphostins increased significantly the number of apoptotic cells. Further experiments have revealed that both the investigated inhibitors increased the percentage of DU145 and A549 cells in S phase of cell cycle, indicating that AG494 and AG1478 arrest cell growth in the G1 phase, similarly to other known inhibitors of EGFR [9, 36, 37]. Furthermore, cell growth arrested in the G1 phase after tyrphostins treatment could lead cancer cells to an apoptotic pathway.

Our results indicate that each of the investigated tyrphostins works differently, both within a single cell line and between the different cell lines. The influence of the inhibitors on the same cell line differs (despite similar mechanism of action - ATP competitors) [37-39] perhaps because they belong to different chemical classes. Reversible AG494 is benzylidene malonitrile [40] and non-reversible AG1478 is anilinoquinazoline [41], with the resulting small differences in chemical structure of the compound. This may cause the difference in a cell's membrane permeability against these inhibitors. Moreover, slight differences in chemical structure alter properties of each tyrphostin to bind to ATP binding pocket. This could be the reason for different kinetics of growth inhibition among both EGFR inhibitors. Our further experiments showed that AG494 and AG1478 act in a reversible manner [data not shown]. After replacement with inhibitor free medium, reinitiation of cell growth was observed, regardless of the concentration of investigated tyrphostins. Thus, the description given by Levitzki and Levitt of the reversibility and irreversibility of certain tyrphostins may be evaluated only according to the inhibition of enzyme activity in a non cellular environment. However, it is a well-documented fact that the action of the inhibitor is dependent on the cell line [42-49]. This may be due to the presence of different mutations in the intracellular signal transduction machinery. One example is the fact that AG1478 has a higher affinity for mutant forms of the receptor (e.g. EGFRvIII) [22, 23] than the wild type form; therefore, the cells with wtEGFR (e.g. A549 cells) [3] will show a weaker growth inhibition after AG494 treatment than in the case of AG1478. Unequivocal interpretation of obtained results is difficult, because the growth, survival and other features of both investigated cells are regulated by several autocrine loops $[1,2,19]$.

\section{Summary}

The effect of tyrphostins AG494 and AG1478 on lung and prostate cancer cell growth is dose dependent. Non-reversible tyrosine kinase inhibitor AG1478 is stronger cytostatically than reversible inhibitor AG494 for target cell lines $\left(\mathrm{IC}_{50}\right.$ of AG1478 is five times lower). Despite the similar mode of action (ATP competitors), the investigated tyrphostins act differently within the same cell line; moreover, the activity of AG494 and AG1478 may vary depending on the cell line. Both kinase inhibitors have a strongly proapoptotic effect in A549 and DU145 cells without cell necrosis. Blockade of only one family of receptors 
(EGFR) is an insufficient factor to the simultaneous inhibition of MAP and PKB/Akt kinase cascades.

\section{Abbreviations used}

EGF - Epidermal Growth Factor; EGFR - Epidermal Growth Factor Receptor; ERK - Extracellular Regulated Kinase; PKB (Akt) — Protein Kinase B; TGF $\alpha$ - Transforming Growth Factor alpha

\section{References}

1. Wu W, O'Reilly MS, Langley RR. Expression of epidermal growth factor (EGF)/transforming growth factor-A by human lung cancer cells determines their response to EGF receptor tyrosine kinase inhibition in the lungs of mice. Mol Cancer Ther. 2007;6:2652-2663.

2. Kisielewska J, Ligęza J, Klein A. The effect of tyrosine kinase inhibitors, tyrphostins: AG1024 and SU1498, on autocrine growth of prostatecancer cells (DU145). Folia Histochem Cytobiol. 2008;46:185-191.

3. Dutta PR, Maity A. Cellular responses to EGFR inhibitors and their relevance to cancer therapy. Cancer Lett. 2007;254:165-177.

4. Ono M, Kuwano M. Molecular Mechanisms of Epidermal Growth Factor Receptor (EGFR) Activation and Response to Gefitinib and Other EGFR-Targeting Drugs. Clin Cancer Res. 2006;12:7242-7251.

5. Heist RS. Christiani, D. EGFR-targeted therapies in lung cancer: predictors of response and toxicity. Pharmacogenomics. 2009;10:59-68.

6. Levitzki A. Protein tyrosine kinase inhibitors as novel therapeutic agents. Pharmacol Ther. 1999;82:231-239.

7. Levitt ML, Koty PP. Tyrosine kinase inhibitors in preclinical development. Invest New Drugs. 1999;19:213-226.

8. Silvestri GA, Rivera MP. Targeted therapy for the treatment of advanced non-small cell lung cancer. A review of the epidermal growth factor receptor antagonists. Chest. 2005;128:3975-3984.

9. Kleinberger-Doron N. Inhibition of Cdk2 activation by selected tyrphostins causes cell cycle arrest at late G1 and S phase. Exp Cell Res. 1998;241:340-351.

10. Gillies RJ. Didier N. Denton M. Determination of cell number in monolayer cultures. Anal Biochem. 1986;159:109-113.

11. Givens KT, Kirada S, Chen AK, Rorhschiller J, Lee DA. Proliferation of human ocular fibroblasts. Invest Ophthalmol Vis Sci. 1990;31:1856-1862.

12. GenScript USA Inc. Double stain apoptosis detection Kit (Hoechst 33342/PI). Available at: http://www.genscript.com/ /index.html. Accessed July 8, 2011.

13. SABiosciences USA, CASE ${ }^{\mathrm{TM}}$ Cellular Activation of Signaling ELISA, User Manual. Available at: http:// //www.sabiosciences.com/manuals/CASE Brochure.pdf. Accessed May 27, 2011.

14. Liebmann JE, Cook JA, Lipschultz C, Teague D, Fisher J, Mitchell JB. Cytotoxic studies of paclitaxel (Taxol) in human tumor cell lines. Br J Cancer. 1993;68:1104-1109.

15. G. Cassinelli, Lanzi C, Supino R et al. Cellular bases of the antitumor activity of the novel taxane IDN 5109 (BAY598862 ) on hormone-refractory prostate cancer. Clin Cancer Res. 2002;8:2647-2654.

16. Wang TH, Wang HS, Soong YK. Paclitaxel-induced cell death: where the cell cycle and apoptosis come together. Cancer. 2000;88:2619-2628.
17. Majsterek I, Pytel D, Błasiak J. Kinazy tyrozynowe. Nowy cel terapii przeciwnowotworowej. Post Bioch. 2005;51:251-260.

18. Vlahovic G, Crawford J. Activation of tyrosine kinase in cancer. Oncologist. 2003;8:531-538.

19. Agarwal R. Cell signaling and regulators of cell cycle as molecular targets for prostate cancer prevention by dietary agents. Biochem Pharmacol. 2000;60:1051-1059.

20. Moscatello DK, Holgado-Madruga M, Godwin AF et al. Frequent expression of a mutant epidermal growth factor receptor in multiple human tumors. Cancer Res. 1995;55:5536-5539.

21. Olapade-Olaopa EO, Moscatello K, MacKay EH et al. Evidence for the differential expression of a variant EGF receptor protein in human prostate cancer. Br J Cancer. 2000;82:186-194.

22. Grandal MV, Zandi R, Pedersen MW, Willumsen BM, van Deurs B, Poulsen HS. EGFRvIII escapes down-regulation due to impaired internalization and sorting to lysosomes. Carcinogenesis. 2007;28:1408-1417.

23. Montgomery RB. Antagonistic and agonistic effects of quinazoline tyrosine kinase inhibitors on mutant EGF receptor function. Int J Cancer. 2002;10:111-117.

24. Nature Publishing Company. Cancer multidrug resistance. Methods Mol Biol. 2010;596:1-14.

25. Fizazi K. The role of Src in prostate cancer. Ann Oncol. 2007;18:1765-1773.

26. Osherov N, Levitzki A. Epidermal-growth-factor-dependent activation of the Src-family kinases. Eur J Biochem. 1994;225:1047-1053.

27. Ma WW, Adjei A. Novel Agents on the Horizon for Cancer Therapy. CA Cancer J Clin. 2009;59:111-137.

28. Guarino M. Src signaling in cancer invasion. J Cell. Physiol. 2010;223:14-26.

29. Shepard HM, Brdlik CM, Schreiber H. Signal integration: a framework for understanding the efficacy of therapeutics targeting the human EGFR family. J Clin Invest. 2008;118:3574.

30. Meier F, Schittek B, Busch S. The Ras/Raf/MEK/ERK and PI3K/AKT signaling pathways present molecular targets fof effective treatment of advanced melanoma. Front Biosci. 2005;10:2986-3001.

31. Yoon S, Seger R. The extracellular signal-regulated kinase: Multiple substrates regulate diverse cellular functions. Growth Factors. 2006;24:21-44.

32. McKay MM, Morrison DK. Integrating signals from RTKs to ERK/MAPK. Oncogene. 2007;26:3113-3121.

33. Pawson T. Dynamic control of signaling by modular adaptor proteins. Curr Opin Cell Biol. 2007;19:112-116.

34. Rini BI, Small EJ. Biology and clinical development of vascular endothelial growth factor-targeted therapy in renal cell carcinoma. J Clin Oncol. 2005;23:1028-1043.

35. Bellezza I. Bracarda S. Caserta C. Minelli A. Targeting of EGFR tyrosine kinase by ZD1839 ("Iressa") in androgenresponsive prostate cancer in vitro. Mol Genetics Metabolism. 2006;88:114-122.

36. Bonaccorsi L, Marchiani S, Muratori M, Fort Baldi E, Gefitinib ('Iressa, ZD1839) inhibits EGF-induced invasion cancer cells by suppressing PI3K/AKT activation. J Cancer Res Clin Oncol. 2004;130:604-614.

37. Klein A, Kisielewska J. Tyrfostiny — drobnocząsteczkowe inhibitory kinaz tyrozynowych. Post Biol Kom. 2007;34:477-494.

38. Klein S, Levitzki A. Targeting the EGFR and the PKB pathway in cancer. Curr Opin Cell Biol. 2009;21:85-193.

39. Johnson LN. Protein kinase inhibitors: contributions from structure to clinical compounds. $Q$ Rev Biophys. 2009;42:1-40.

40. Gazit A, Osherov N, Gilon C, Levitzki A. Tyrphostins. 6. Dimeric benzylidenemalononitryle tyrphostins: potent 
inhibitors of EGF receptor tyrosine kinase in vitro. $J$ Med Chem. 1996;39:4905-4911.

41. Ellis AG, Doherty MM, Walker F et al. Preclinical analysis of the analinoquinazoline AG1478, a specific small molecule inhibitor of EGF receptor tyrosine kinase. Biochem Pharmacol. 2006;71:1422-1434.

42. Shushan A, Rojansky N, Laufer N et al. The AG1478 tyrosine kinase inhibitor is an effective suppressor of leiomyoma cell growth. Hum Reprod. 2004;19:1957-1967.

43. Zhou Y, Brattain M. Synergy of epidermal growth factor receptor kinase inhibitor AG1478 and ErbB2 kinase inhibitor AG879 in human colon carcinoma cells is associated with induction of apoptosis. Cancer Res. 2005;65:5848-5856.

44. Zhang Du, Fang. Jin. Tian. Tyrphostin AG1478 suprpresses proliferation and invasion of human breast cancer cells. Int J Oncol. 2008;33:595-602.

45. Zhu XF, Liu ZC, Xie BF et al. EGFR tyrosine kinase inhibitor AG1478 inhibits cell proliferation and arrests cell cycle in nasopharyngeal carcinoma cells. Cancer Lett. 2001:10; 169:27-32.

46. Berezowska S, Diermeier-Daucher S, Brockhoff $\mathrm{G}$ et al. Effect of additional inhibition of human epidermal growth factor receptor 2 with the bispecific tyrosine kinase inhibitor AEE788 on the resistance to specific EGFR inhibition in glioma cells. Int J Mol Med. 2010;26:713-721.

47. Steinbach JP, Klumpp A, Wolburg H, Weller M. Inhibition of epidermal growth factor receptor signaling protects human malignant glioma cells from hypoxia-induced cell death. Cancer Res. 2004;64:1575-1580.

48. Grandal MV, Zandi R, Pedersen MW, Willumsen BM, van Deurs B, Poulsen HS. EGFRvIII escapes down-regulation due to impaired internalization and sorting to lysosomes. Carcinogenesis. 2007;28:1408-1417.

49. Montgomery RB. Antagonistic and agonistic effects of quinazoline tyrosine kinase inhibitors on mutant EGF receptor function. Int J Cancer. 2002;10:111-117.

Submitted: 29 September, 2011 Accepted after reviews: 22 February, 2012 